\title{
Hydrological Risks in Natural Hazards Focused on the Role of the Water: Studies on Landslides
}

\author{
Luis Sousa, Eurípedes Vargas Jr., Rita Sousa, and Helder I. Chaminé
}

\begin{abstract}
Landslides are one of the most important natural hazards on Earth. Landslide mechanisms related to hydrology are analyzed with a focus on the major risks, and formal risk assessment methodologies are presented. The management of accidents in slopes is discussed, with particular emphasis on Hong Kong and to Rio de Janeiro. Specific aspects of slope instability in the state of Rio de Janeiro are discussed, with a focus on cases that occurred in the mountainous region of the State. The megadisaster occurred in 2011, with high number of deaths and significant economic losses, is studied with particular incidence in individual landslides. A description of occurrence of large landslides in China is also presented. The modeling of catastrophic flow-type slide at Shenzhen landfill induced by intense rainfall is introduced and referred to large number of landslides happened during the Wenchuan earthquake in 2008 is mentioned.
\end{abstract}

\section{Keywords}

Natural hazard - Hydrological risk - Groundwater • Landslide - Earthquake

L. Sousa $(\bowtie)$

Department of Geotechnical Engineering, Tongji University,

Shanghai, China

e-mail: sousa-scu@hotmail.com

E. Vargas Jr.

Department of Civil Engineering, Catholic University of Rio de Janeiro, Rio de Janeiro, Brazil

R. Sousa

Department of Civil, Environmental and Ocean Engineering,

Stevens Institute of Technology, Hoboken, USA

H. I. Chaminé

Laboratory of Cartography and Applied Geology, Department of Geotechnical Engineering, School of Engineering (ISEP), P.Porto, Porto, Portugal

\section{Introduction}

Landslides are one of the most important geotechnical risks on Earth. Landslides are difficult to predict because their initiation depends on many factors and on the interaction between these factors. To satisfy the societal demand for protection against landslides, it is necessary to systematically assess and manage landslide hazard and risk. This can be done using principles of decision making under uncertainty.

The presence of water is one of the major triggers. The hydrologic response of a slope to rainfall is very complex and depends on a great number of factors, both on local and catchment basin scales. Figure 1 illustrates some of these factors. In this study landslide mechanisms related to hydrology are analyzed with a focus on the major risks, and formal risk assessment methodologies are presented. Concepts concerning the problem of risk management in slopes are also highlighted. The existing experience in Hong Kong is reported, as well in Rio de Janeiro city, with emphases the important activity of the Geo-Rio Foundation. Specific aspects of slope instability occurring in the State of Rio de Janeiro, with incidence in the mountainous region are discussed. Also, important events that occurred in China are illustrated.

\section{Risk and Risk Assessment}

The systematic risk assessment and management in slopes is essential to ensure the safety of such systems. The risk assessment begins with the site selection. During the design and planning stages, it is necessary to evaluate risks associated to the geology and to obtain information on-site that provides the input necessary for the risk assessment evaluation. The stage related to the identification and description of threats will be the next step, in order to evaluate risks and the formal incorporation of uncertainties in the slope issue. The problem of risk identification models, in particular with 


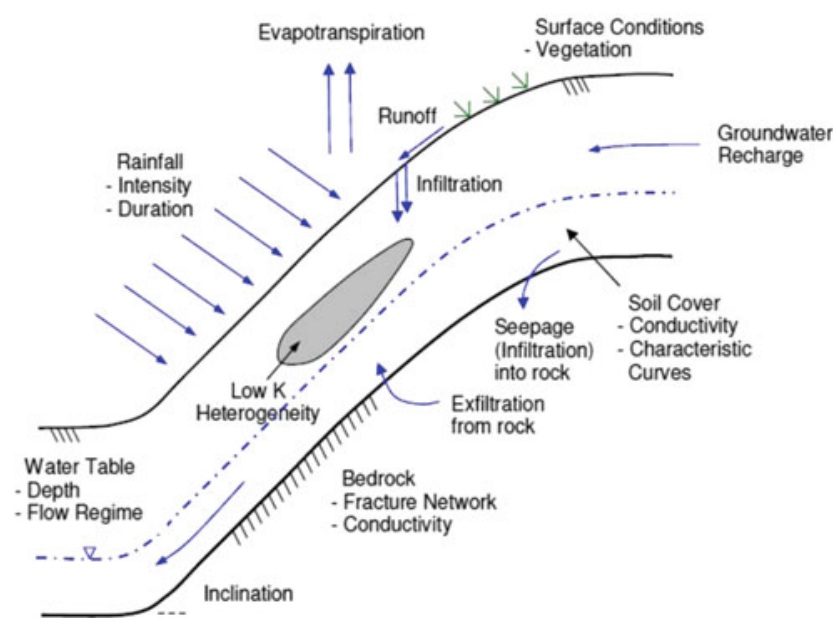

Fig. 1 Factors affecting slopes due to rainfall. Adapted from Karam (2005)

regard to instability mechanisms, deterministic and probabilistic models, geotechnical risk identification and risk management.

The identification and description of accidents in slopes are very important, with the collection of information on movements and geometry of accidents. The establishment of databases with accidents and their structuring aiming the application of Data Mining techniques (DM) and the direct description of the instability of slopes is processed in order to analyze the risk. Special focus is given to various DM techniques, with special emphasis on Neuronal and Bayesian Networks (BN). The use of the probabilistic techniques of $\mathrm{BN}$ is relevant in order to manage the risk and sensitivity analyses are recommended. The application of a $\mathrm{BN}$ to a decision problem in slope instability is well illustrated in Einstein and Sousa (2012).

Risk assessment and risk management for slopes requires an initial step the identification of the threats that are possible which can lead to detrimental consequences. The major threats are in general associated to precipitation, subsequent infiltration and groundwater flow (Sousa et al. 2017). The occurrence of earthquakes can be very relevant as a triggered factor (He et al. 2019).

\section{Management of Accidents in Slopes}

Natural or constructed slopes are defined as inclined surfaces in rocks or soils, or mixed masses originated from geological, geomorphological and human action processes. The project of a slope involves the collection of geological and geotechnical information, the evaluation of the resistance properties of the formations and discontinuities and the presence of the water with emphasis on the pluviometric regime.
For slope movements, there are several classifications (e.g., Bronnimann 2011). The risk management practice is described for Hong Kong region and the city of Rio de Janeiro.

Honk Kong is a region of China with a large population density, in a territory of only $1100 \mathrm{~km}^{2}$, and very mountainous. About $75 \%$ of the territory has slopes greater than $15^{\circ}$ and more than $30 \%$ has slopes greater than $30^{\circ}$. There is a history of tragic accidents in the slopes. The territory has a tradition of a high standard in the practice of slope engineering. The establishment of an efficient security system developed by Geotechnical Engineering Office (GEO) was established in the territory. In each year GEO reported hundreds of slope instabilities, whose data are stored on a database, being the large majority relatively small although larger slips occur, with more than $5000 \mathrm{~m}^{3}$. It was also introduced as a long-term program designated Landslide Preventive Measures to systematically analyze the slopes of government works and perform a safety analysis of private works. Maintenance programs were established by the various governmental sectors. The definition of risk reduction strategies is one of the most relevant activities being developed in order to avoid or eliminate certain accidents and includes stabilization, mitigation; this is a reduction of vulnerability, and the establishment of warning systems (Sousa et al. 2013). Detailed risk analyses are made consistently in the territory, as well as the establishment of guidelines for the study of accidents. A flowchart of the slope stabilization actions is illustrated in Fig. 2.

The city of Rio de Janeiro is another important situation in terms of hydrological risks. The occupation of hills and slopes throughout its history has been promoted. The occurrence of serious geotechnical accidents, particularly of

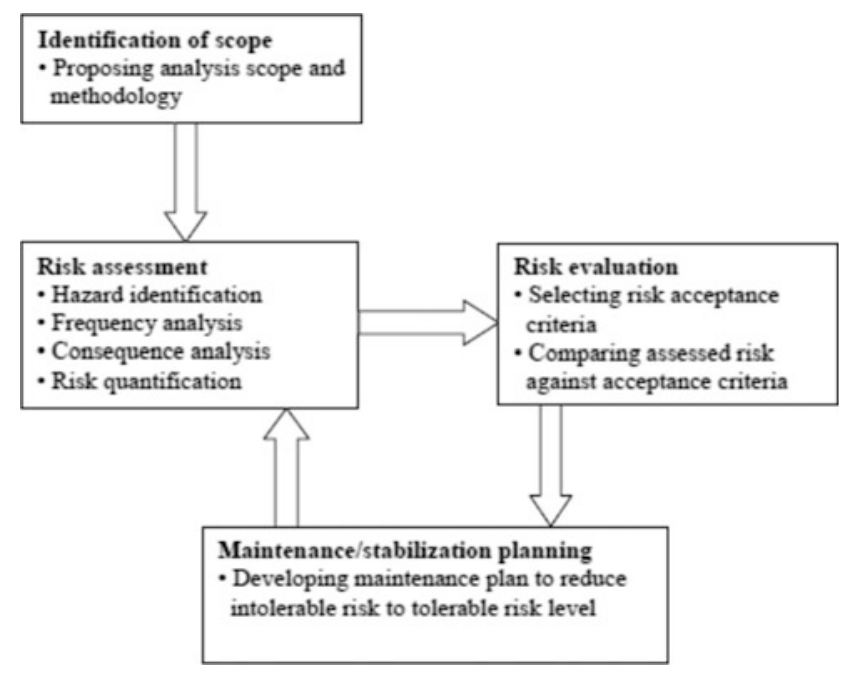

Fig. 2 A general flowchart of slope stabilization actions 
falling blocks, derives from its unique and complex geographic and morphological characteristics. The studies conducted through surface mapping showed high susceptibility to rock falls. Sometimes there have been observed tears in the slopes during dry periods, and interpretative models originated in thermal actions were proposed. Several containment works have been carried out, as buttresses.

Almost 45 years ago, the Instituto de Geotécnica, a division of the Municipality of Rio de Janeiro, later renamed the Geo-Rio Foundation, was founded. Its creation occurred after severe rainy events that occurred in the city in 1966. Since then, the technical staff formed by engineers and geologists conducts surveys and defines the necessary works to ensure the safety of the population. Geo-Rio has implemented the Rio Alert system, which maintains pluviometric stations scattered throughout the city to monitor the rains (Fig. 3). Meteorological radar images are critical to the detection of storms. A radar is located in Sumaré, and its images are updated every two minutes and allow observing the location, displacement, and intensity of precipitation.

\section{Instabilities of Slopes in Rio de Janeiro State}

In 2010 and 2011, more than 1000 people died in natural disasters in the State of Rio de Janeiro, like in Angra dos Reis, in Niterói and in the mountainous region of the State. The megadisaster of the mountainous region of the State occurred between the 11th and 12th of January 2011, reaching seven cities mainly Nova Friburgo, Teresópolis, and Petrópolis and it was considered one of the larger events of generalized mass movements in Brazil (Sousa et al. 2013).

According to the documents of the time, doubts arose about what caused the disaster in the proportions that occurred and, in particular, on the factors that led to so many human losses. The region has always been characterized by a great natural vulnerability, located in the Serra do Mar, formed by rocks with a thin layer of land and covered by Atlantic forest, with high slope and heavy rainfall regime in summer, characteristics that generate soils more unstable and prone to landslides.

The urban slides that occurred affected slopes in the base of mid-slope elevations between $30^{\circ}$ and $45^{\circ}$, which proved their associated high risk. In Fig. 4, aspects of the planar slipway occurred in Três Irmãos in 2012, responsible for the destruction of some buildings in the vicinity of the accident is evidenced.

\section{Landslides in China}

Considerable disasters due to landslides occurred in China. Flow-type landslides happened in several parts of China like in Gansu, China, in 2010 and recently a large flow-type occurred at a municipal solid waste in Guangming New District of Shenzhen, China. The landfill accident in Shenzhen that happened on December 20, 2015 caused the missing of 70 people and presumed dead and the destruction of 33 buildings ( $\mathrm{Li}$ et al. 2018). The disaster involved an area with $1100 \mathrm{~m}$ in length and $630 \mathrm{~m}$ in maximum width. Figure 5 shows results of a numerical study of the accident $(\mathrm{Li}$ et al. 2018).

Earthquakes may trigger thousands of landslides in mountainous regions in the case of strong ground motion and associated not favorable geomorphic environment. This was what happens during the 2008 Wenchuan earthquake that occurred in Sichuan province, China. Most of catastrophic landslides were distributed along the central Longmen Shan fault system in a mountainous region, at the eastern margin of the Tibetan Plateau. The earthquake resulted in a large number of landslides and caused significant economic damage and it was the most important earthquake that had occurred in China. More than 60,000 landslides were triggered by the earthquake. The sudden damming of rivers by the generated landslides caused
Fig. 3 Network of pluviometric stations at Rio de Janeiro Sousa et al. (2013)

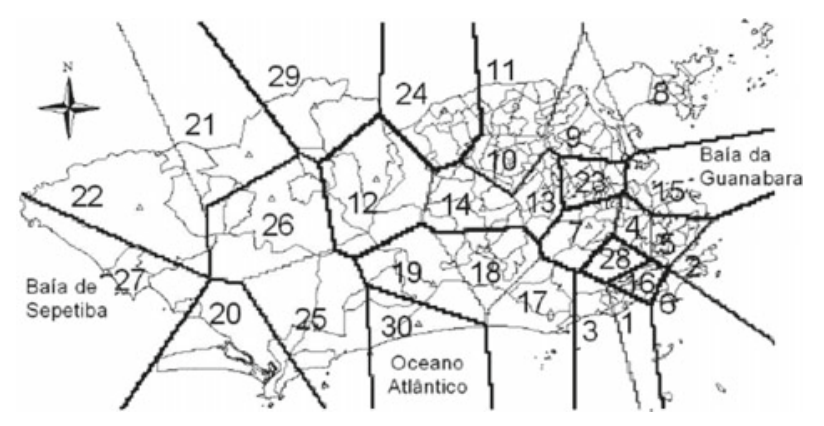

17 Itanhangá 18 Cidade de Deus 19 Rio Centro 20 Guaratiba 21 Gericinó 22 Santa Cruz 23 Cachambi

24 Anchita 25 Grota Funda 26 Campo Grande 27 Sepetiba 28 Sumaré 29 Mandanha 30 Itaúna 


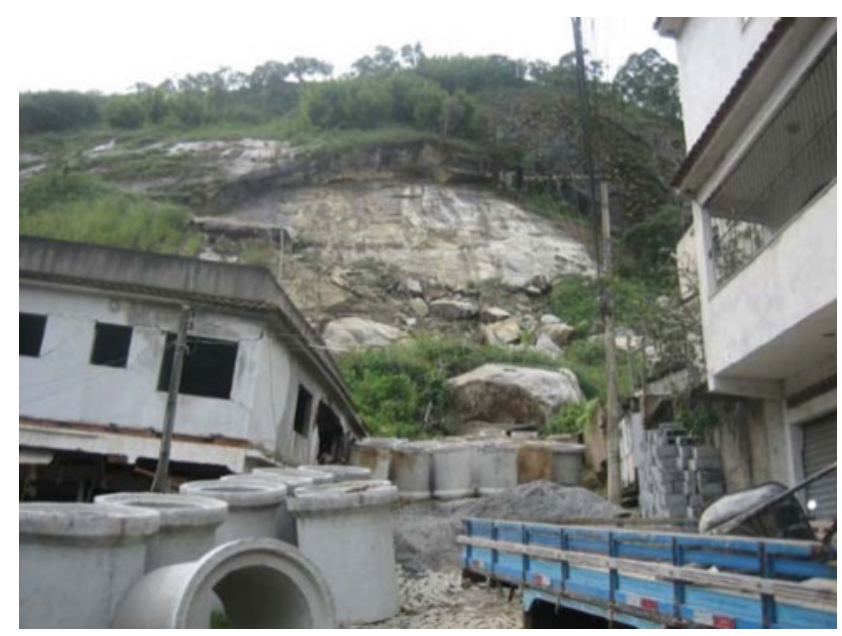

Fig. 4 View of the landslide at Três Irmãos (Brazil)

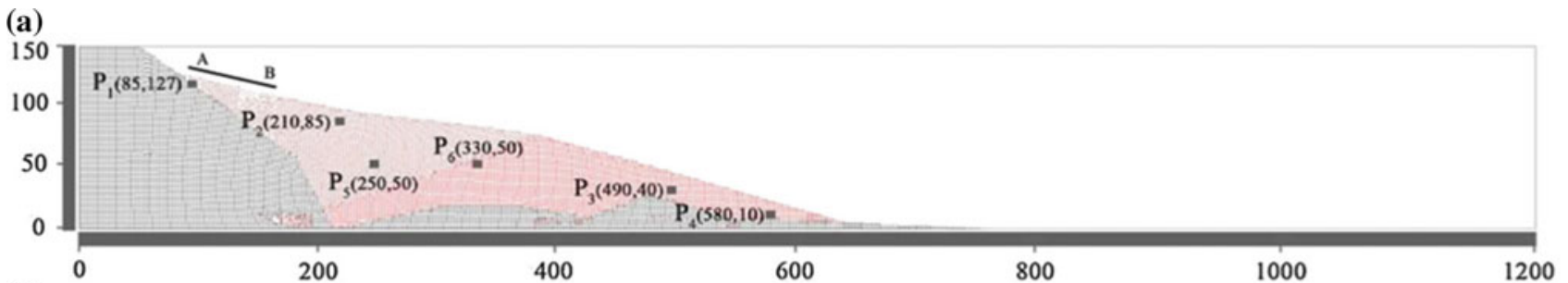

(b)

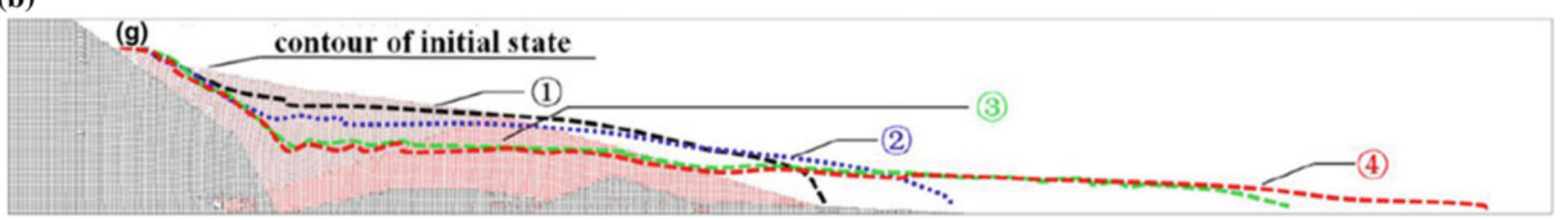

Fig. 5 Flowslide at Shenzhen: a numerical modeling; b flow configuration at different times Li et al. (2018)

flooding and generated a large number of landslide dams, more than 800. A description of more significant landslides is referred with focus on the Daguangbao landslide, involving a volume of $7.4 \times 10^{8} \mathrm{~m}^{3}$. Numerical simulations were performed for understanding the kinetic mechanism that occurred at the Daguangbao landslide using MPM (Material Point Method) models using 2D and 3D approaches (He et al. 2019).

\section{Concluding Remarks}

This work focuses on hydrological risks of landslides. The presence of water is one of the major triggers. Landslide mechanisms related to hydrology are analyzed, and formal risk assessment methodologies are highlighted. The management of accidents in slopes is discussed, with emphasis on Hong Kong and to Rio de Janeiro sites. Specific aspects of slope instability in the state of Rio de Janeiro are discussed, with incidence to cases occurred in the mountainous region of the State. A description of occurrence of large landslides in China is also presented.

\section{References}

Bronnimann C (2011) Effect of groundwater on landslide triggering. Federal School of Lausanne. Swiss, 223. (Ph.D. thesis)

Einstein HH, Sousa RL (2012) Risk in slopes. In Ribeiro e Sousa L, Vargas E Jr, Fernandes MM, Azevedo R (eds) Proceedings of the Innovative Numerical Modelling in Geomechanics, CRC Press, pp 201-210

He M, Sousa LR, Muller A, Vargas Jr E, Sousa RL, Sousa Oliveira C, Gong W (2019) Numerical and numerical models and safety considerations for Daguangbao landslide triggered by the 2008 Wenchuan earthquake (submitted and in revision) 
Karam K (2005) Landslide risk assessment and uncertainties. MIT, USA, 747. (Ph.D thesis)

Li ZH, Jiang YJ, Lv Q, Sousa LR, He MC (2018) Consistent modelling of catastrophic flowslide at the Shenzhen landfill using a hydro-elastoplastic model with solid-fluid transition. Acta Geotech 13(6):1451-1466
Sousa LR, Vargas Jr E, Sousa RL (2013) Analysis and risk management of slopes at Rio de Janeiro State. PUC-Rio, Report, 122 (in Portuguese)

Sousa LR, Sousa R, Vargas E Jr, Velloso R, Karam K (2017) Risk assessment on $\mathrm{CO}_{2}$ injection processes and storage. Rock Mech Rock Eng 12:359-397 